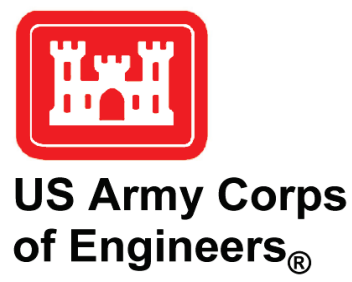

\title{
Modeling Ship-Wake-Induced Sediment Transport and Morphological Change - Sediment Module in FUNWAVE-TVD
}

by Matt Malej, Fengyan Shi, and Jane M. Smith

PURPOSE: This technical note documents the sediment transport module and morphological module developed in the Boussinesq wave model, FUNWAVE-TVD. The sediment transport module is based on the quasi-steady flow assumption, which is believed to be a more appropriate model for predicting sediment transport in the swash zone and ship-wake-induced shoreline erosion. It includes the suspended sediment transport and bedload sediment transport. The morphological module calculates morphological evolution based on the sediment continuity equation. This technical note also provides model validations and an example for simulating ship-wake-induced sediment transport and morphological changes. This technical note is considered an interim product that will eventually be turned into a full technical report with more validation and verification work, in particular for the case of cohesive sediment transport and morphology change.

INTRODUCTION: Two types of sediment transport models have been developed under the FUNWAVE model framework. Long and Kirby (2006) developed a coupled Boussinesq/bottom boundary layer model for surface wave-induced sediment transport and morphological changes in near-shore regions. The model is based on the curvilinear version of FUNWAVE (Shi et al. 2001) and calculates the bed-load and suspended-load transport rates using instantaneous bed shear stress in a generalized curvilinear coordinate framework. Recently, a sediment transport model for predicting nearshore seabed changes induced by co-seismic tsunamis has been developed by Tehranirad et al. (2016). The sediment transport model coupled with FUNWAVE-TVD (through multi-nesting from the Spherical coordinates to the Cartesian coordinates) successfully reproduced the deposition/erosion patterns in the Crescent City Harbor after the 2011 Tohoku tsunami. This model is based on the quasi-steady flow assumption and is particularly applicable to sediment transport induced by longer waves relative to wind wave periods.

The model validations in Tehranirad et al. (2018) indicated that the quasi-steady flow-based sediment transport model is more accurate for predicting the morphological changes due to swash motion, compared with the bottom boundary layer-based sediment transport model, which is suitable for the surfzone. According to the wave characteristics of ship wakes, the quasi-steady flow-based sediment transport model such as in Kobayashi and Tega (2002) is believed to be a more appropriate model for simulating ship-wake-induced shoreline erosion because shoreline erosion occurs at the swash zone or river banks. In this study, the focus was on the ship-wakeinduced sediment transport and shoreline erosions and thus re-implemented the sediment transport and morphological modules in the present version of FUNWAVE-TVD, which has already included the ship-wake generation.

The sediment transport model implemented here solves an advection-diffusion depth-averaged sediment concentration equation. It uses van Rijn's (1984) pickup function to calculate sediment erosion rate and Cao's (1999) formula to estimate sediment deposition rate. Bedload 
sediment transport is calculated using Meyer-Peter and Müller's (1948) formulation. The bed evolution module is based on the sediment continuity equation and uses time-averaged pickup and deposition rates to compute morphological changes. For spatial discretization of the advection-diffusion equation, there was an implementation of both the upwinding and Monotonic Upwind Scheme for Conservation Laws - Total Variation Diminishing schemes. A third-order Runge-Kutta scheme for time-stepping was used, which is consistent with the existing numerical schemes applied in FUNWAVE-TVD. Also considered was an avalanche scheme as the slope limiting method for the bed and coastline erosions, as well as a hard bottom methodology to account for non-erodible regions.

The model validations for the sediment transport and morphological modules are included in Tehranirad et al. (2016), who conducted simulations of Kobayashi and Lawrence's (2004) experiment, Pintado-Patiño et al.'s (2017) experiment, and the field test case of the 2011 tsunamiinduced morphological changes in Crescent City Harbor, CA. For ship-wake-induced shoreline erosions, there currently are no data; work is proceeding on obtaining future field data tests through ongoing field work done by the U.S. Army Corps of Engineers in Mobile Bay and the Houston Ship Channel. An idealized example was used to demonstrate the model setup and the shipwake-induced sediment transport regime, along with the resulting impact on shoreline erosion.

SEDIMENT TRANSPORT MODEL: The sediment transport module calculates sediment transport induced by both suspended load and bedload. The morphological module calculates the bed evolution based on sediment continuity equation.

Suspended Sediment Motion. The suspended sediment motion is governed by the depthaveraged sediment concentration equation, which includes terms of the horizontal advective flux, horizontal sediment diffusion, pickup, and deposition rates. The pickup rate is calculated using van Rijn's (1984) pickup function. The deposition rate is evaluated using the formula of Cao (1999).

Parameters needed for the suspended sediment transport module are (1) median grain size, $D_{50}$; (2) critical Shields parameter, $\theta_{c r}$ (default: 0.055); (3) water density, $\rho_{w}$ (default: 1027 kilograms per cubic meter $\left[\mathrm{m}^{3}\right]$ ); (4) density ratio of grain and water, $s$ (default: 2.68); and (5) sediment settling velocity, $w_{s}$. Note that a default value will be used if a parameter is not specified in the model input file.

Bedload Sediment Transport. The bedload sediment transport can be calculated using several bedload sediment transport formulas developed for steady flows. As stated in Soulsby (1997), those formulas can be used on an instantaneous basis in tidal flows, and under waves or combined waves and currents, because the response time of a sand grain in bedload motion is very short compared to a tidal period or a wave period. In the test cases that follow, Meyer-Peter and Müller's (1948) bedload transport formula was used to estimate the bedload sediment transport rate and its effect on bed evolution. The critical Shields parameter for bedload transport, $\theta_{c r b}$, needs to be specified; otherwise, a default value of 0.047 will be used.

Morphological Evolution. Morphological evolution is computed using the sediment continuity equation, in which the time-averaged pickup and deposition rates are used. The time integration for the sediment continuity equation is performed with a morphological time-step. In Tehranirad et al. (2018), the morphological time-step is recommended to be larger than the hydrodynamic time-step, yet small enough to capture bed changes induced by tsunami waves. In ship-wake applications, 
however, the morphological time-step is kept the same as the hydrodynamic time-step in terms of short wave applications. A specific range of morphological time-step for ship-wake applications needs a further investigation based on numerical simulations carried out against measured data. To calculate morphological evolution, sediment porosity, $n$, needs to be specified in the model; otherwise, a default value of $n=0.47$ will be used.

Slope Limiting Methodology. Slope limiting methodology is a useful avalanching algorithm to control the maximum bottom slope for modeling sea bed and shoreline evolution. By definition, the bottom slope cannot exceed the repose angle of the sediment, $\theta_{r}$. Avalanching occurs to reform a bed with the maximum slope equal to the sediment repose angle. The repose angle is dependent on the sand grain properties, usually being between $30^{\circ}$ to $40^{\circ}$ (Splinter et al. 2011) and can be given to the model as an input parameter. The default value in the model is $\theta_{r}=35^{\circ}$, or $\tan \theta_{r}=0.70$.

Non-Erodible Bed. Non-erodible bed can be specified in the morphological module to represent some non-erodible coastal structures such as breakwaters, sea walls, and concrete constructions. An erodible layer with a thickness of $Z_{s}$ is defined in a computational domain.

Ship-Wake Generation. Ship-wake generation was documented in Shi et al. (2018). It follows Ertekin et al. (1986), Wu (1987), and Torsvik et al. (2006) and applies a pressure source in the Boussinesq equations.

To model ship wakes, a user needs to create a vessel file, which contains the information about vessel length, width, draft, and time series of vessel path, following the instruction provided in the FUNWAVE WIKI page mentioned at the end of the report.

VALIDATION: As far as the authors are concerned, there is no readily available measured data for validation of ship-wake-induced sediment transport and morphological changes. Some of the ongoing and planned laboratory and field studies carried out by the U.S. Army Corps of Engineers should provide valuable validation data sets in the near future. Presented here are two validation cases carried out by Tehranirad et al. (2018). One is the simulation of the dambreak-induced sediment transport based on the laboratory experiment by Pintado-Patiño et al. (2017), see Figure 1. The other is the simulation of tsunami-induced morphology change in the Crescent City Harbor during the 2011 Tohoku tsunami event. The modeled morphology change is verified against field data.

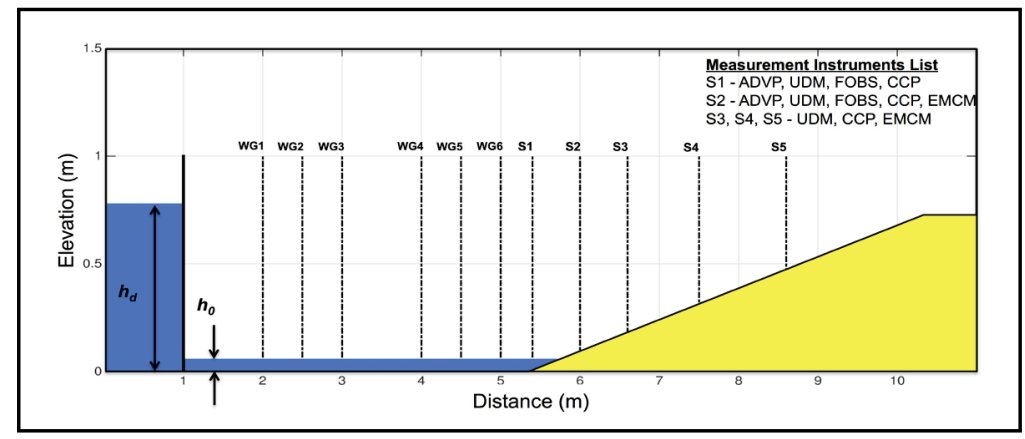

Figure 1. Pintado-Patiño et al. (2017) dam-break experiment setup. 
Dam-Break-Induced Sediment Transport. Dam-break-induced sediment transport is modeled based on the physical experiment conducted in a flume at the Center for Applied Coastal Research, University of Delaware. The flume was 16 meters $(\mathrm{m})$ long, $0.6 \mathrm{~m}$ wide, and $0.80 \mathrm{~m}$ deep. Figure 1 illustrates the experimental setup. The reservoir behind the gate contained a water volume of $0.468 \mathrm{~m}^{3}\left(h_{d}=0.78 \mathrm{~m}\right)$ at the upstream section, as opposed to the flat downstream section with $h_{0}=0.06 \mathrm{~m}$ initial water depth. Following the opening of the gate, the dam-break wave was generated. This process created a turbulent bore with an approximate flow speed of $U$ $=2.0$ meters per second $(\mathrm{m} / \mathrm{s})$ and $0.25 \mathrm{~m}$ water depth. The turbulent bore then collapsed onto a planar sand beach, causing a swash event similar to those found on natural beaches. The beach was built with a steep 1:7 planar slope, composed of very well sorted medium silica sand with the median grain size of $d_{50}=0.40$ millimeter (mm). Five stations ( $\mathrm{S} 1$ to $\mathrm{S} 5$ shown in Figure 1) were deployed with co-located instruments across the beach profile to measure flow and sand related quantities over the sandy slope. The suspended sediment concentration fraction was measured at stations S1 and S2 using Fiber Optical Backscatter Sensors (FOBS).

A one-dimensional (1D) simulation was carried out using FUNWAVE-TVD with grid dimensions of $1100 \times 3$ in the $\mathrm{x}$ and $\mathrm{y}$ directions ( 3 is required in the $\mathrm{y}$ direction for 1D simulation) and grid size of $\Delta \mathrm{x}=\Delta \mathrm{y}=1 \mathrm{~cm}$, corresponding to $11 \mathrm{~m}$ long flume, in which the experiments were conducted.

The initial water elevation was set up as the same as in the experiment. The median grain size of $D_{50}=0.4 \mathrm{~mm}$ was used in the model, and the fall velocity was calculated to be $w_{s}=0.0514$ $\mathrm{m} / \mathrm{s}$ using Rubey's (1933) formula. The numerical results include time series of surface elevation, velocity field, sediment concentration, and depth changes. Detailed model/data comparisons have been performed in Tehranirad et al. (2018). Shown here are model/data comparisons of sediment concentration and bed changes to demonstrate the model fidelity in modeling bore-induced sediment motion on a beach.

Figure 2 shows the comparison of depth-averaged sediment concentration between the model and the FOBS data at station S1 and S2. Note that FOBS recorded the sediment concentration from 1 to 10 centimeters $(\mathrm{cm})$ above the bed. To calculate the depth-averaged sediment concentration, concentration values in the water column above $10 \mathrm{~cm}$ are needed. Tehranirad et al. (2018) used sediment concentration values extrapolated from the measurements from 1 to $10 \mathrm{~cm}$ above the bed to calculate the depth-averaged concentration, using the exponential profile assumption. The model captured the magnitude of sediment concentration at both Station S1 and S2, indicating that the quasi-steady state flow-based sediment transport model is appropriate for wash flowinduced sediment transport. Although the model predicted the second peak occurring earlier than the measurement, the magnitudes of the concentration are still comparable to the data. 


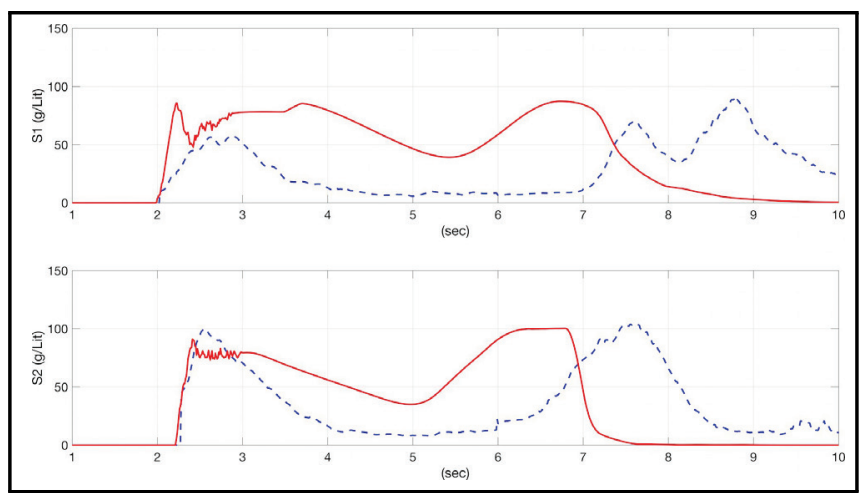

Figure 2. Comparison between measured depthaveraged sediment concentrations (blue dotted lines) recorded with FOBS and computed values (solid red lines) at stations S1 and S2 Tehranirad et al. (2016).

In the laboratory experiment, a second gate at the beach toe was used, right after the first runuprundown process finished, in order to block the reflected bore from the upstream end of the experiment setup. In the model, however, it is difficult to simulate the action of the second gate. Therefore, the model results were only comparable to measured data before the reflected wave reached the beach toe (approximately 10 seconds [s] of simulation). Figure 3 shows bed changes after the rundown of the first wave and before the reflected wave reaches the beach profile. The model result indicates the dam bore erodes the shoreface and deposits the eroded sand close to the slope toe, consistent with the data. The simulated bed elevations at $10 \mathrm{~s}$ are generally less than measured values because there is still a significant amount of suspended sediment in the water column. The modeled elevation after all suspended sediment settles provides better agreement with the data, though the reflection effect is a concern.

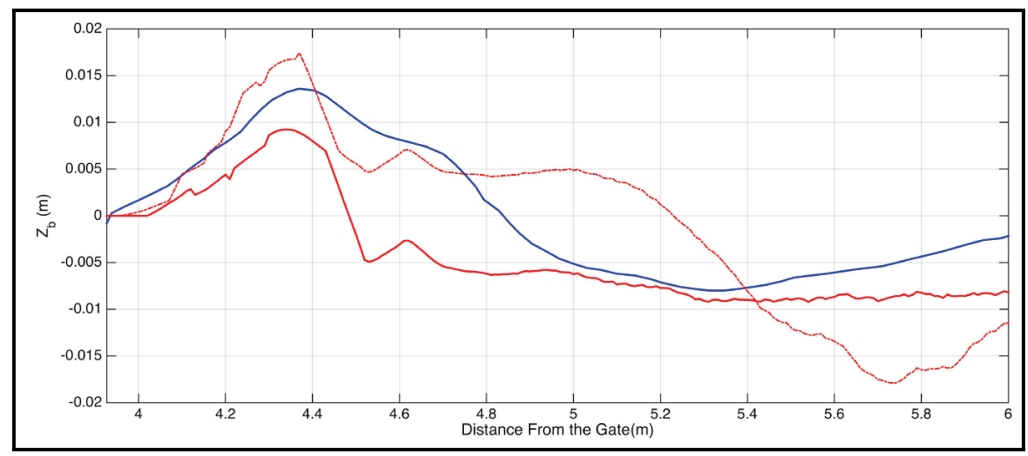

Figure 3. Comparison between measured bed changes (solid blue line) and calculated $Z_{b}$ after $10 \mathrm{~s}$ of simulation (solid red line) and after all the suspended sediment deposits on the bed (red dotted line), which is influenced by reflection effects (Tehranirad et al. 2016). 
Tohokuoki Tsunami-Induced Morphological Change. Tohokuoki tsunami-induced morphological change in Crescent City Harbor was simulated using a nesting grid system, which contained five levels of one-way nesting grids from coarse to fine resolutions. The coarsest grid had a resolution of 16 arc-seconds and covered a region of $129^{\circ} \mathrm{W}-122^{\circ} \mathrm{W}$ and $38^{\circ} \mathrm{N}-45^{\circ} \mathrm{N}$. The coarsest grid model was forced by the results from the basin-scale model of Grilli et al. (2013). The finest grid had a resolution of $1 / 6$ arc-second $(3.83 \mathrm{~m} \times 5.05 \mathrm{~m})$ and covered the entire domain of the Crescent City Harbor. Detailed model setup, sediment parameters, and model results can be found in Tehranirad et al. (2018). Here, a model/data is used to demonstrate the capability of the model in predicting sediment transport and morphological change in complex bathymetric conditions.

A model/data comparison of the morphological change before and after the tsunami event can be made between Figure 4, which is from the observation of Wilson et al. (2012), and Figure 5, which is the modeled morphological changes. Both figures show a comparison from two surveys done across a 3-year time span. However, there were no significant changes to the harbor morphology from the NOAA 2008 and the USACE 2010 surveys, which supports the claim of most morphological changes occurring during the tsunami event itself. In addition, the use of a 2008 survey, as a more complete data set, was therefore justified (Wilson et al. 2012). The model result shows significant erosion near the jetties in the entrance of the harbor, similar to the field observation. The largest erosion depths were calculated on the back side of the jetty in the mid harbor entrance and along the mouth of the small boat basin, with erosions between 2 to $3 \mathrm{~m}$. The model also calculated a significant amount of sediment deposition inside the boat basins, parallel to observations. In general, the model was able to capture the trend of erosion and deposition patterns inside Crescent City Harbor, although larger erosions were observed in the field survey. Based on the analysis in Tehranirad et al. (2018), possible reasons causing the discrepancies between the model and data could be the low grid resolution for modeling scour holes and the shorter modeling period (6 hours of simulation time versus 3 days of tsunamiinduced long wave event due to the computational overhead and the difficulty in resolving edge waves in the basin-scale domain). 


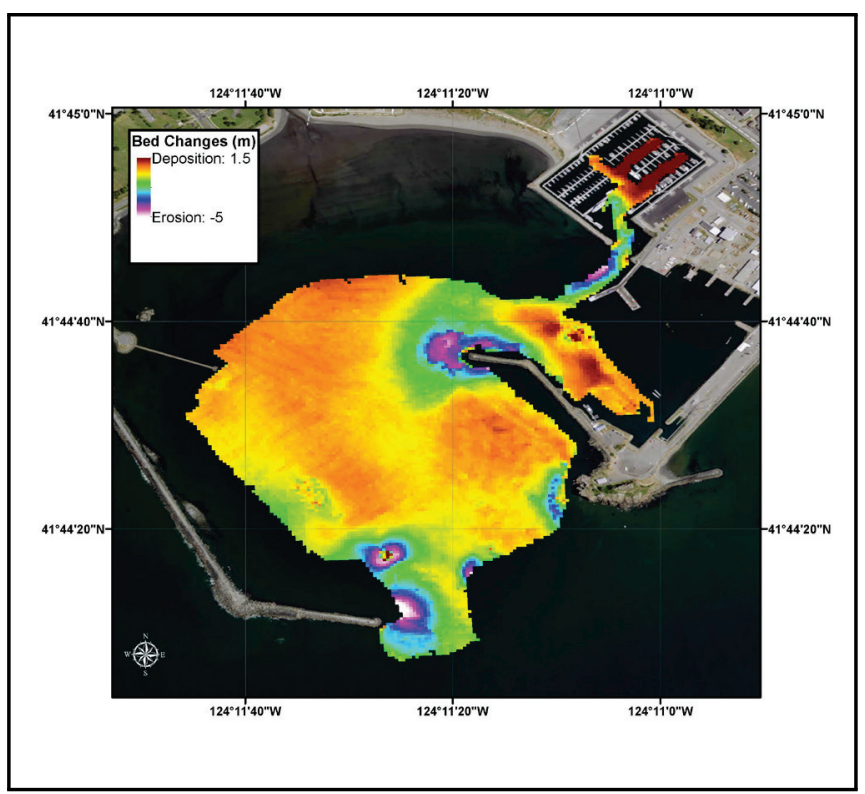

Figure 4. Bed changes inside Crescent City Harbor during the 2011 tsunami, determined from the difference of two surveys performed in 2008 (NOAA 2008) and in March 2011

(NOAA 2011; Wilson et al. 2012)

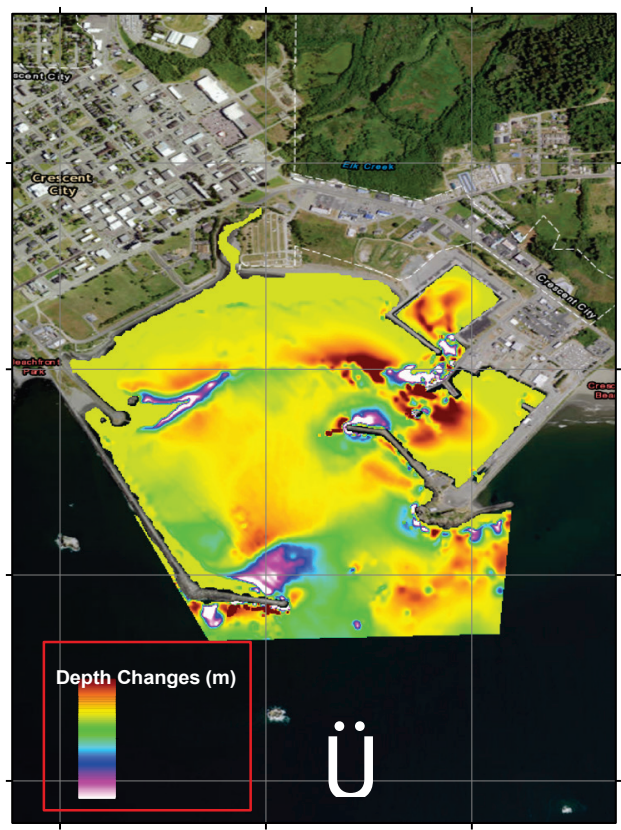

Figure 5. Computed bed changes in Crescent City Harbor during 2011 Tohoku-Oki Tsunami. Green, blue, purple, and white colors represent the eroded areas (Tehranirad et al. 2016). 
EXAMPLE FOR SHIP-WAKE-INDUCED SEDIMENT TRANSPORT: To demonstrate the model application to ship-wake-induced sediment transport, simulations of waves generated by fast vessels moving in a narrow channel with slopping beaches on two sides were carried out. Figure 6 shows the section view (left) and planar view (right) of the computational domain, respectively. The domain is $4800 \mathrm{~m}$ long and $120 \mathrm{~m}$ wide. The deep channel is $3 \mathrm{~m}$ deep and $20 \mathrm{~m}$ wide, located at the center of the domain. The beach slope $\tan \theta=0.06$, which resulted in a narrow swash zone in the domain $y$ directions. A sponge layer of $50 \mathrm{~m}$ was applied on the left side. Two cases were tested. One was a case with a single vessel. The other was a case with multiple vessels, where six identical vessels were used to investigate the effects of morphological changes. The vessel had a length of $10 \mathrm{~m}$, width or beam of $5 \mathrm{~m}$, and draft of $1.5 \mathrm{~m}$. The shape parameters $\alpha=\beta=0.5$, which represent the block ratio $C_{B}=0.5$ calculated based on Shi et al. (2018). The vessel was prescribed to move from left to right along the central line of the channel with a supercritical speed of $7.0 \mathrm{~m} / \mathrm{s}$ (Froude number $F_{r}=1.3$ ).

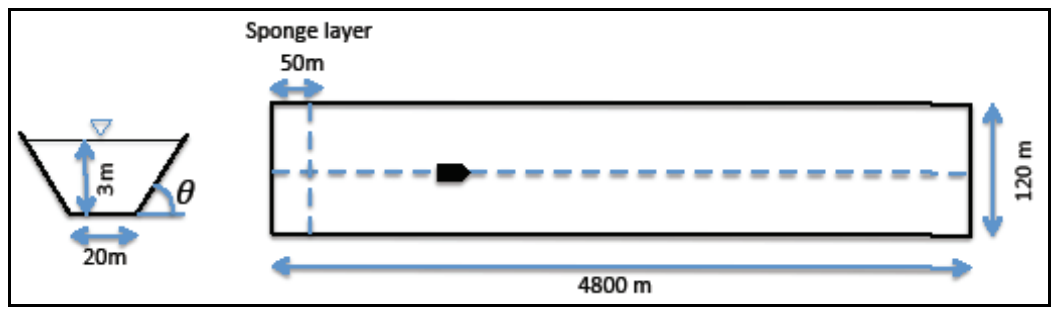

Figure 6. Left: section view of the channel; right: plane view of the channel.

The simulation can be performed in a half of the domain due to the symmetric configuration. The model setup for the central/main module (Boussinesq solver) of FUNWAVE-TVD can be specified in the driver 'input.txt' file:

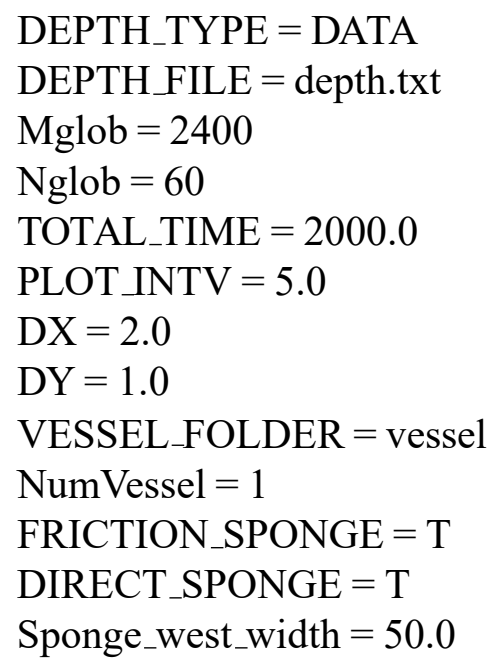

! depth type

! file containing the bathymetry profile

! dimension in $\mathrm{x}$ direction

! dimension in y direction (half domain)

! total simulation time $(\mathrm{sec})$

! output time interval

! grid size in $\mathrm{x}$ direction

! grid size in y direction

! directory for vessel file

! number of vessels, use 6 for the multi-vessel case

! friction type sponge layer

! direct sponge layer

! sponge layer width at west boundary

The parameters for the sediment module can also be specified in the driver 'input.txt' file. The exclamation mark (!) at the beginning of a line represents comment lines disregarded by FUNWAVE-TVD and in the absence of parametric input, system-specific default values are used. 


\begin{tabular}{|c|c|}
\hline $\mathrm{D} 50=0.0005$ & ! median grain size \\
\hline Sdensity $=2.68$ & ! density ratio \\
\hline $\mathrm{WS}=0.0125$ & ! settling velocity \\
\hline Shields_cr $=0.055$ & ! critical Shields parameter \\
\hline Shields_crb $=0.055$ & ! bedload critical Shields \\
\hline parameter Bed Change $=\mathrm{T}$ & ! bed change logical parameter \\
\hline $\begin{array}{l}\text { Morph_step }=10 \\
\text { porosity }=0.47\end{array}$ & $\begin{array}{l}\text { ! ratio of sediment time step to Morphological time step, default: } 1 \mathrm{n} \\
\text { ! sediment porosity }\end{array}$ \\
\hline Avalanche $=\mathrm{F}$ & ! Avalanche logical parameter, default: False \\
\hline Tan $\_$phi $=0.7$ & ! tangent of repose angle, default: 0.7 (equating to 35 degrees) \\
\hline Hard_bottom $=\mathrm{F}$ & ! logical parameter for hard bottom, default:False \\
\hline Sed_Scheme $=$ Upwinding & ! numerical scheme for sediment module, default: Upwinding \\
\hline PLOT_INTV_SEDIMENT = & ! time interval for sediment module output \\
\hline
\end{tabular}

The parameters for the vessel are set separately in the file (e.g., vessel_00001 for the case of single vessel, located in the vessel directory vessel [specified in input.txt as shown in the central module setup]) :

Title: Vessel \# 1

Blue_Star_I

Length (m), Width(m), Alpha(m), Beta(m), A(m)

$20.0,10.0,0.5,0.5,1.0$

Time, $\mathrm{X}(\mathrm{m}), \mathrm{Y}(\mathrm{m})$ (relative to the origin of the coordinates)

0.040 .060 .0

25523.0180040 .060 .0

The file contains the vessel dimensions (length and width), parameters $\alpha$ and $\beta$, draft $A$, and the time series of the path (Time, $\mathrm{X}$ and $\mathrm{Y}$ ). For the case of six vessels, the user should specifiy NumVessel $=6$ in input.txt and provide six vessel files, which contain different releasing time. In the test, vessels are released every $100 \mathrm{~s}$.

Figure 7 shows snapshots of waves generated by the vessel and the sediment concentration that uses logarithmic color scale (base 10). The model predicts Kelvin wake patterns behind the vessel and reflected waves from the beaches. Different from the case of Shi et al. (2018), who conducted a similar ship-wake simulation but with a constant water depth and vertical walls on the sides, a steady bore is generated in front of the vessel in the present case. Shi et al. (2018) showed soliton generations with the same Froude number and wave breaking concentrated at the first soliton front. The difference may be caused by the sloping beach in this configuration, versus the vertical walls in Shi et al. (2018), in which the mach reflection enhances the soliton generation. In the present case, wave breaking is concentrated at the shoreline and is more intense compared to the case with flat bottom. High wave particle velocities and wave breaking on the banks can stir up more sediment and thus cause high sediment concentration at the shoreline, especially in the swash zone. Sediment concentration gradually decreases as the vessel moves far away due to sediment deposition. 


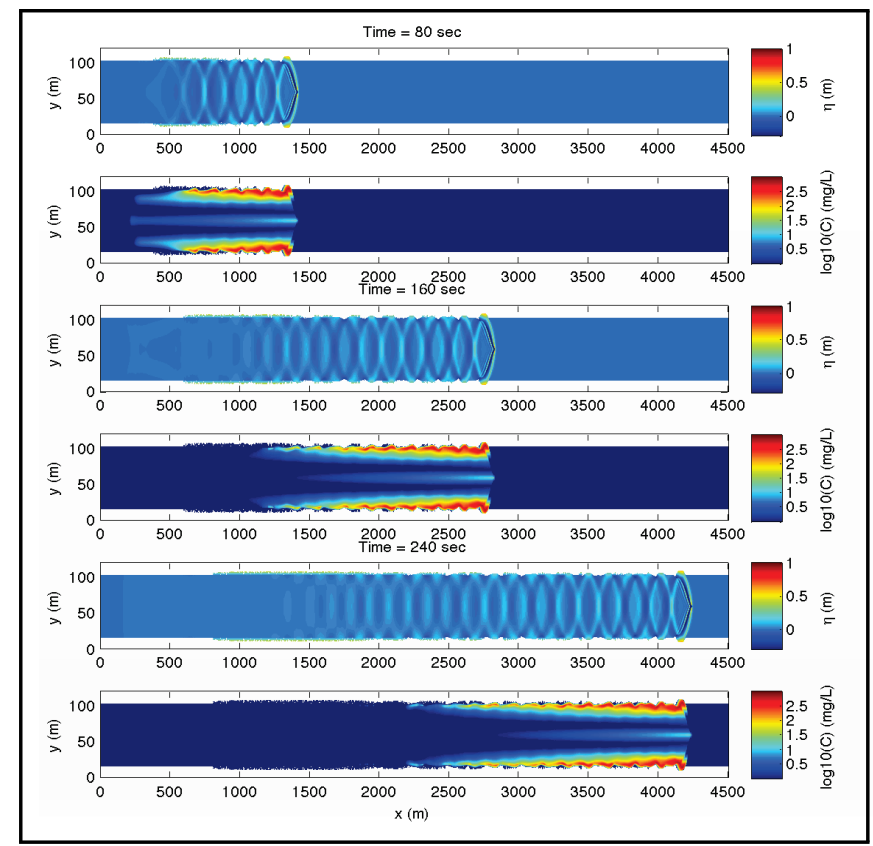

Figure 7. Time snapshots of surface elevation and sediment concentration in the case of single vessel.

Figure 8 shows results from the case of six vessels. It illustrates, respectively, sediment concentration, suspended load-induced bed changes, bedload-induced bed changes, and the bed changes induced by total load (from top to bottom). Because vessels move closely in space (released every $100 \mathrm{~s}$ ), the sediment concentration induced by the multiple vessels increases downstream as shown in the top panel. Correspondingly, bed changes also show an increasing trend from upstream to downstream in both suspended load and bedload (two middle panels). The bedload-induced bed changes are smaller than that induced by the suspended load in this case. More sediment deposits downstream compared to upstream because of the higher sediment concentration and the longer time period of settling.

The averaged stream-wise bed change is shown in Figure 9 (top panel), along with the channel depth and wave envelope (red dashed lines, bottom panel). The maximum erosion occurs at the beach edge, close to the lower envelope. Sediment accretion is found on both sides of the erosion area, around the upper wave envelope and below the lower envelope. This sediment erosion/deposition pattern needs to be confirmed by field observations. 


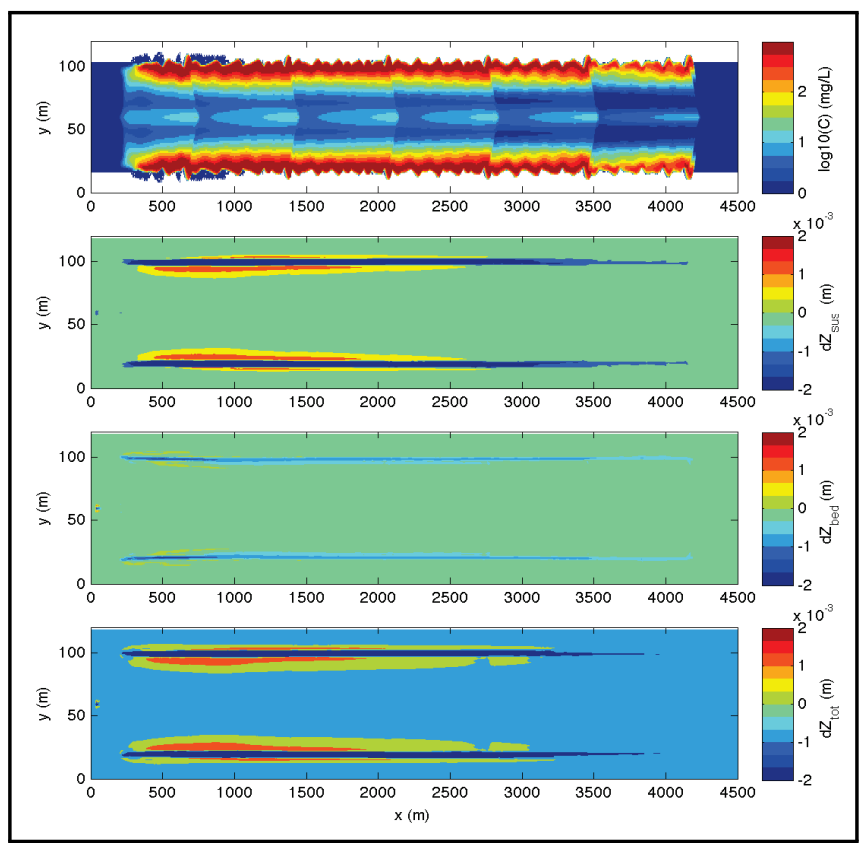

Figure 8. Snapshots of sediment concentration, suspended load-induced bed change, bedload-induced bed change, and bed change induced by total load (from top to bottom) in the case of six vessels.

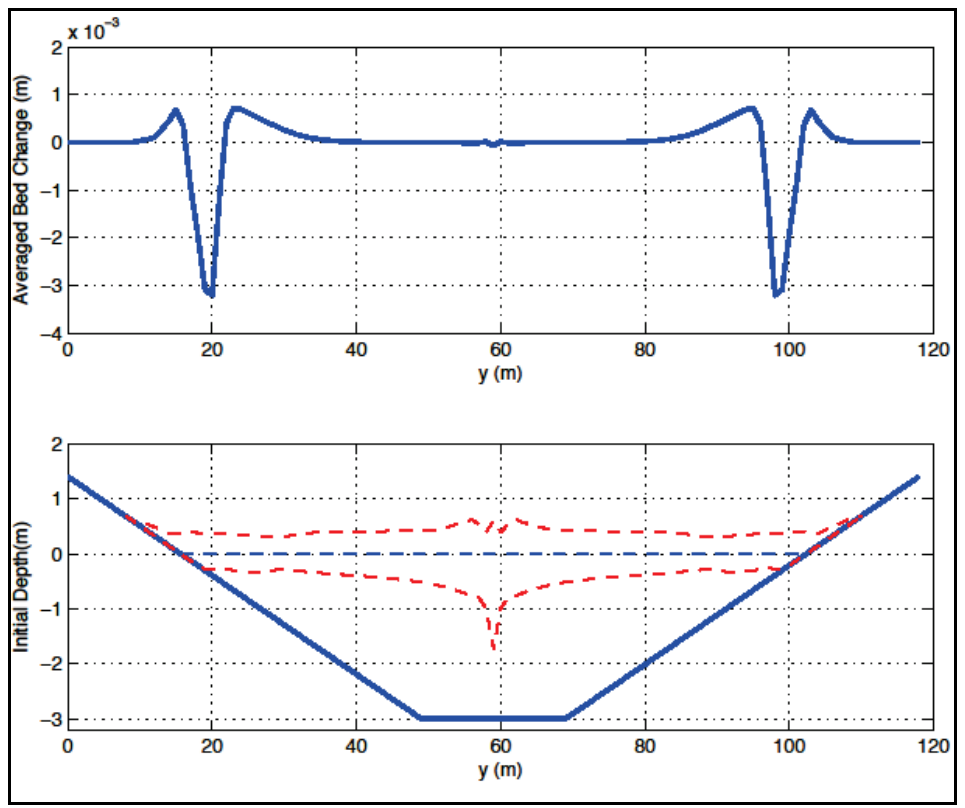

Figure 9. (Top) Stream-wise-averaged bed change distribution across the channel. (Bottom) Channel bathymetry and wave envelope (dashed lines). 
FUTURE WORK: The sediment module in FUNWAVE-TVD was validated using limited laboratory data of long wave or bore-induced sediment transport and bed changes. The U.S. Army Engineer Research and Development Center (ERDC) has been collecting field data of sediment transport and the associated morphological evolution induced by vessels. Laboratory experiments are currently being planned for ship-wakes on a plane beach and associated sediment transport estimation. FUNWAVE-TVD and the sediment transport module will be further validated when the data are available.

In addition, the sediment transport module implemented in this study was based on the dynamics of sand transport and may not be suitable for modeling fine-grained sediment dynamics, such as cohesive sediment transport. The future model development will address ship-wake-induced sediment transport in a wide range of sediment regimes. The progress of the future model implementation will be updated timely on the FUNWAVE-TVD Wiki page: https://chl.erdc. dren.mil/funwave-tvd - redirect to the University of Delaware FUNWAVE Wiki.

ADDITIONAL INFORMATION: This CHETN is a product of the Navigation Systems Research Program being executed by the U.S. Army Engineer Research and Development Center, Coastal and Hydraulics Laboratory. Questions about this technical note can be addressed to Dr. Matt Malej (Voice: 603-646-4455; email: Matt.Malej@usace.army.mil). For information about the Navigations Systems (NavSys) Program, please contact the NavSys Manager, Mr. Charles E. Wiggins (Voice: 601-634-2471; email: Charles.E.Wiggins@usace.army.mil). This technical note should be cited as follows:

Malej, M., F. Shi, and J. M. Smith. 2019. Modeling Ship-Wake-Induced Sediment Transport and Morphological Change - Sediment Module in FUNWAVE-TVD. ERDC/CHL CHETN-VII-20. Vicksburg, MS: U.S. Army Engineer Research and Development Center. http://dx.doi.org/10.21079/11681/32911.

\section{REFERENCES}

Cao, Z. 1999. "Equilibrium Near-Bed Concentration of Suspended Sediment." Journal of Hydraulic Engineering 125(12): 1270-1278.

Ertekin, R. C., W. C. Webster, and J. V. Wehausen. 1986. "Waves Caused by a Moving Disturbance in a Shallow Channel of Finite Width.” J. Fluid Mech. 169: 275-292.

Grilli, S. T., J. C. Harris, T. Bakhsh, T. L. Masterlark, C. Kyriakopoulus, J. T. Kirby, and F. Shi. 2013. "Numerical Simulation of the 2011 Tohoku Tsunami Based on a New Transient FEM Co-Seismic Source: Comparison to Far- and Near-Field Observation." Pure and Applied Geophysics 170(6-8): 1333-1359.

Kobayashi, N., and A. R. Lawrence. 2004. “Cross-Shore Sediment Transport under Breaking Solitary Waves.” Journal of Geophysical Research 109(C3): C03047.

Kobayashi, N., and Y. Tega. 2002. "Sand Suspension and Transport on Equilibrium Beach." J. Waterway, Port, Coastal, Ocean Eng. 128(6): 238-248

Long, W., and J. T. Kirby. 2006. Boussinesq Modeling of Waves, Currents and Sediment Transport. Research Report No. CACR-06-02. Center for Applied Coastal Research, Dept. of Civil and Environmental Engineering, Univ. of Delaware, Newark.

Meyer-Peter, E., and R. Müller. 1948. "Formulas for Bed-Load Transport." Proc., 2nd Meeting, IAHR, Stockholm, Sweden, 39-64. 
Pintado-Patiño, J. C. 2017. Procesos Dinámicos en la Zona de Swash: Un Estudio Integral. PhD thesis. Univesidad Nacional Autónoma de México.

Rubey, W. W. 1933. "Settling Velocity of Gravel, Sand, and Silt Particles." American Journal of Science 148: 325338.

Shi, F., R. A. Dalrymple, J. T. Kirby, Q. Chen, and A. Kennedy. 2001. "A Fully Nonlinear Boussinesq Model in Generalized Curvilinear Coordinates." Coastal Engineering 42(4): 237-258.

Shi, F., M. Malej, J. M. Smith, and J. T. Kirby. 2018. "Breaking of Ship Bores in a Boussinesq-type Ship-Wake Model." CoastalEngineering 132: 1-12.

Soulsby, R. 1997. Dynamics of Marine Sands. Thomas Telford Publications.

Splinter, K. D., M. L. Palmsten, R. A. Holman, and R. B. Tomlinson. 2011. "Comparison of Measured and Modeled Run-Up and Resulting Dune Erosion during a Lab Experiment." Proceeding of the Coastal Sediment. World Scientific.

Tehranirad, B., J. T. Kirby, and F. Shi. 2016. Does Morphological Adjustment during Tsunami Inundation Increase Levels of Hazard? Research Report No.CACR-16-02. Center of Applied Coastal Research, Department of Civil and Environmental Engineering, University of Delaware.

Torsvik, T. 2006. Long Wave Models with Application to High Speed Vessels in Shallow Water. PhD thesis. University of Bergen, Norway.

van Rijn, L. C. 1984. "Sediment Pick-Up Functions." Journal of Hydraulic Engineering 110(10): 1494-1502.

Wilson, R., C. Davenport, and B. Jaffe. 2012. "Sediment Scour and Deposition within Harbors in California (USA), Caused by the March 11,2011, Tohokuoki Tsunami." Sedimentary Geology 282: 228-240.

Wu, T. Y. 1987. "Generation of Upstream Advancing Solitons by Moving Disturbances." J. Fluid Mech. 184: 7599.

NOTE: The contents of this technical note are not to be used for advertising, publication,

or promotional purposes. Citation of trade names does not constitute an official endorsement or approval of the use of such products. 